\title{
IDENTIDADE, ESPAÇO E TEMPO: OS LIMIARES DA PARATOPIA NO DISCURSO FILOSÓFICO
}

Márcio Rogério Oliveira CANO Reynaldo de Azevedo GOSMÃO

\section{Introdução}

A problemática acerca das formas como os discursos se constituem, se são equivalentes e como se inscrevem no universo discursivo, é tema da Análise do Discurso (AD) desde a sua constituição e vem tomando centralidade nas últimas décadas. Alicerçada nos discursos políticos, durante muito tempo, a $\mathrm{AD}$ se voltou para entender como tais discursos que, embora complexos, têm sua existência no cotidiano social e como se mostram organizados na sua especificidade. Os questionamentos acerca do discurso político se deram, em especial, pela necessidade de se compreender as relações de poder estabelecidas e geradoras de efeitos de sentidos que interpelavam os sujeitos de forma a assujeitá-los. Esse quadro ini- 
cial começa a ser superado, ou ampliado, na medida em que outros pesquisadores começam a se despontar na área trazendo outras perspectivas resultantes de análises de outros discursos, como o religioso, literário, jornalístico, acadêmico, racista, científico etc. $\mathrm{O}$ olhar sobre esses outros discursos possibilitou também, além de muitos questionamentos, a necessidade de compreender se eles estão ou não na mesma dimensão de organização e como se inscrevem no contínuo histórico-social.

É nesse contexto, em busca, de entender a não equivalência dos discursos na forma como se organiza e agem na constituição dos sujeitos e das relações sociodiscursivas que nossa pesquisa se constrói. Nossos estudos se voltam para pesquisar sobre os diferentes lugares que ocupam e as diferentes estratégias do dizer que são mobilizadas por tais lugares. Falamos, portanto, dos discursos paratópicos, tópicos e atópicos.

Especificamente, neste capítulo, mostraremos os resultados de uma pesquisa focada na paratopia. Para tanto, partimos da compreensão de que a interação está interligada a "posicionamentos que os enunciadores possuem em determinadas práticas discursivas" (CANO, 2012, p. 13). Segundo Maingueneau (1997), as instituições, assim como o sujeito, se comunicam por meio de contratos que são atravessados pelo contexto histórico, evidenciando condições de produção "implícito e partilhado pelos interlocutores" (MAINGUENEAU, 1997, p. 30), o que nos impõe a conclusão de que, dadas as diferentes condições de produção, um discurso pode ter diferentes status de poder na sociedade, assumindo lugar de dar sentido ao fazer social (paratópico), de utilizar e debater os sentidos dados ao fazer social (topia) ou ter os sentidos marginalizados, mas que constituem o fazer social (atopia). 
Como mencionado, nosso foco está nos discursos que dão sentido ao fazer social, portanto, paratópicos. Segundo Maingueneau (2010), os discursos paratópicos são o religioso, literário, científico e filosófico. Embora apontando essas quatro dimensões, $\mathrm{o}$ autor em um primeiro momento se aprofundou mais em seus estudos sobre o discurso religioso (MAINGUENEAU, 2007), sem no entanto, nesse primeiro momento, discutir a paratopia. Partiu, depois, para os outros discursos paratópicos, deixando um espaço para outros discursos que pouco foi explorado nessa mesma perspectiva. Dada a problemática e vitalidade dos estudos sobre os discursos paratópicos, procuramos dar nossa contribuição a partir do discurso filosófico. Entendemos tal discurso como constituinte, ou seja, é um discurso que se autovalida e se autoconstitui, além de não ter necessidade de retomar ou recorrer a quaisquer outros discursos para sua existência. É, portanto, um discurso de grande poder, pois possui a incumbência de dar sentido à vida por meio dos modos de se pensar sobre e no mundo, de como o mundo e a humanidade se constroem.

Por isso, postulamos a seguintes perguntas de pesquisa: Como o discurso filosófico se constitui? O que o caracteriza como discurso paratópico? Quais estratégias de dizer marcam sua inserção no universo discursivo? Para responder as questões, utilizamos os conceitos de paratopia de identidade, espacial e temporal, especialmente, a partir das obras de Dominique Maingueneau (1997, 2010, 2018), aplicadas ao corpus constituído da obra A História da Sexualidade: a vontade de saber, publicada em 1988, do filósofo Michel Foucault. A relevância desse estudo se revela por meio das possíveis contribuições para ampliação de conceitos usados em análise do discurso e por meio da análise exploratória do discurso filosófico. 


\section{Observações preliminares sobre o discurso filosófico}

Compreender o discurso filosófico como paratópico aponta, primeiramente, para a necessidade de tomarmos um conceito do que é filosofia. Para tanto, traremos alguns movimentos do discurso filosófico, que regularmente se consolida por meio de um domínio ou uma lógica específica, embora não seja um discurso isolado. A filosofia se autoconstitui em seu dizer, mas está em concorrência com outros discursos, mesmo assumindo um lugar acima dos outros.

O discurso filosófico se formula a partir de um constructo de autoridade, de enunciados particulares, melhor dizendo, para que se apreenda um conceito dentro de uma corrente filosófica, se faz necessário compreender a lógica filosófica de determinado autor, não sendo um saber vulgarizado e de interpretação ampla.

Como ferramenta para validação da lógica filosófica, são criadas algumas condições de acessibilidade ao discurso filosófico, por exemplo, manuais, dicionários específicos de algumas áreas, obras em que autores se propõem realizar releituras mais acessíveis de uma fonte "originária", que são condições de interpenetração, ou seja, permitem uma aproximação de um saber, por mais que o caminho não seja a própria obra.

Segundo Maingueneau (2018, p. 67), a obra filosófica, “tende a absorver sua enunciação em seu enunciado, isto é, seu conteúdo doutrinal, reservando-se, todavia, a possibilidade de reverter sua doutrina em enunciação", dito de outro modo, a filosofia coloca na letra (no escrito) sua essência, construindo um caráter dialético, paradoxal, dicotômico que se torna um regime de constituência que se encarrega em tornar o pensamento filosófico em irredutível. 
De acordo com o dicionário de Filosofia de Abbagnano (2007) o conceito de filosofia perpassa:

FILOSOFIA (gr. (pita>ao(pioc; lat. Philosophia; in. Phüosophy, fr. Philosophie, ai. Philosophie, it. Filosofia). A disparidade das F. tem por reflexo, obviamente, a disparidade de significações de "F.", o que não impede reconhecer nelas algumas constantes. Destas, a que mais se presta a relacionar e articular os diferentes significados desse termo é a definição contida no Eutidemo de Platão: F. é o uso do saber em proveito do homem (...) É necessária, portanto, uma ciência em que coincidam fazer e saber utilizar o que é feito, e esta ciência é a F. (Eutid., 288 e 290 d) (...) na definição de Descartes, segundo a qual "esta palavra significa o estudo da sabedoria, $e$ por sabedoria não se entende somente a prudência nas coisas, mas um perfeito conhecimento de todas as coisas que o homem pode conhecer, tanto para a conduta de sua vida quanto para a conservação de sua saúde e a invenção de todas as artes" (Princ. phil., Pref.). Encontram-se igualmente na definição de Hobbes, segundo a: qual a F. é, por um lado, o conhecimento causal e, por outro, a utilização desse conhecimento em benefício do homem (De corp., I, $\$ 2,6$ ), bem como na de Kant, que define o conceito cósmico da F. (o conceito que interessa necessariamente a todos os homens) como o de "ciência da relação do conhecimento à finalidade essencial da razão humana" (Crít. R. Pura, Doutr. transe, do método, cap. III). 
Em função desses objetivos, o discurso filosófico estabelece regras fundamentais, nas quais, a filosofia passa a ser compreendida como fonte legítima do saber, que fica evidente na definição de Descartes. A filosofia é compreendida como "um perfeito conhecimento de todas as coisas que o homem pode conhecer, tanto para a conduta de sua vida quanto para a conservação de sua saúde e a invenção de todas as artes” (ABBAGNANO, 2007, p. 447).

Entretanto, a filosofia por absorver objetos externos para criar suas investigações sua visada é dialética por manter diálogos com campos como a metafísica, ontologia, gnosiologia, metodologia, ética, estética, existencialismo, fenomenologia, entre outros campos, o que permite ao pensamento filosófico extrapolar a lógica do mundo das ideias e da realidade "dando sentido aos atos de seus membros" (MAINGUENEAU, 2010, p. 158).

A complexidade desse discurso traz à tona a emergência do filósofo, entidade, também, particularmente complexa. A autoridade prevista na filosofia precisa configurar a autoridade constituinte do autor, pregada à figura paradoxal do autor enquanto sujeito doutrinador que precisa negar sua fragilidade no mundo cotidiano. Ao se fazer como sua própria essência, a filosofia e o filósofo precisam estar na essência da emergência do discurso, dado o seu caráter doutrinal que possibilita o "conhecimento para o homem se conhecer". Ao mesmo tempo o filósofo é a fonte da essência do conhecimento que faz com que ele mesmo, enquanto homem, se conheça melhor, ocupando o lugar de existência e não existência ao mesmo tempo.

O comprometimento dessa complexidade faz também emergir um modo especial de interdiscurso, que veremos a seguir. 


\section{$A$ rede interdiscursiva}

O discurso filosófico é em si interdiscursivo, como estabelece o primado do interdiscurso para a Análise do Discurso. Por exemplo, para que haja a filosofia política é necessário retomar concepção da ciência política. Estudos filosóficos que tratam de aspectos como a vida e a morte, a violência, os estados de arte, estética, ética etc. precisam de outras áreas para serem discutidos. Assim, a filosofia utiliza de outros campos do saber para análise de um objeto, mas em seu regime de constituência, a filosofia se apropria do que está fora e cria um processo de enunciação, pensamento e lógica que são próprios. Por meio do movimento filosófico, Maingueneau exemplifica que o discurso filosófico se empenha em "explicitar as condições de possibilidade de toda constituição discursiva, incluindo a sua própria” (MAINGUENEAU, 2018, p. 65). Por isso, atua no limite da interdiscursividade, de modo paradoxal, elevando objetos comuns a um status de absoluto, "cujo autor deve ele próprio manter paratópico para poder enunciar o que anuncia" (MAINGUENEAU, 2010, p. 160).

Sendo assim, o discurso filosófico engloba outros discursos sociais, absorvendo esses outros discursos, reposicionando-os em lugar "outro", lugar construído e repensado por meio de uma atividade de criação enunciativa. Para Maingueneau (1997, p. 32) "ao enunciar, eu me concedo um certo lugar e atribuo um lugar complementar ao outro, peço-lhe que se mantenha nele" e que reconheça exatamente aquele que fala de meu lugar.

A função enunciativa garante ao sujeito as circunstâncias de validações discursivas. Terminologias utilizadas em áreas específicas do conhecimento ou um conceito adotado por um filósofo são alguns dos artifícios que podem ser utilizados para gerar efeito de credibilidade para determinada enunciação, inclusive, por meio 
das escolhas das palavras, "o exercício deste discurso pressupõe um lugar de enunciação afetado por determinadas capacidades, de tal forma que qualquer indivíduo, a partir do momento que o ocupa, supostamente as detém" (MAINGUENEAU, 1997, p. 37).

Os campos do conhecimento não têm como prisma apenas um saber, sendo ele original e específico, uma vez que retoma interdiscursivamente outros discursos para dar sentido às coisas do cotidiano, porém o discurso filosófico tem em sua marcação enunciativa um modo de dizer diferente de outros discursos, que precisa ser retomado em sua própria fonte para sua interpretação e sentido.

Sendo assim, a partir de percursos históricos, obras e textos têm suas capacidades discursivas afetadas, tornando-se um "dispositivo constitutivo da construção do sentido e dos sujeitos que aí se reconhecem" (MAINGUENEAU, 1997, p. 50). Segundo o primado do interdiscurso, não existe uma única fonte do dizer, mas sim, são vários conhecimentos imbricados e utilizados discursivamente. Porém, nota-se um esforço no discurso filosófico, no seu processo de enunciação em validar, o próprio discurso, como um discurso inaugural.

O discurso inaugura-se de uma falta original, o sujeito busca, na linguagem, modos e sentidos que gerem efeitos de uma completude, mas essa busca pela completude por meio do discurso só é possível entre um eu e um outro, sendo uma busca atravessada pela diferença, uma vez que esse outro também é faltoso, arbitrário e incompleto, colocando o discurso sempre em um estado dinâmico.

De modo geral, o discurso é uma instância que contém variações, pois dentro de um discurso existem outros que o encapsulam 
ou são encapsulados por ele. Refletem, dessa forma, marcadores que configuram sua historicidade e que constitui uma identidade discursiva através dos registros que são retomados na materialidade discursiva. Por isso, "toda formação discursiva é associada a uma memória discursiva, constituída de formulações que repetem, recusam e transformam outras formulações" (MAINGUENEAU, 1997, p. 115).

O discurso em sua essência nunca deixa de ser um interdiscurso, neste contexto buscar-se-á o discurso a um nível constitutivo do interdiscurso, como apresenta Maingueneau:

"a incorporar elementos pré-construídos, produzidos por fora dela, com eles provocando sua redefinição e redirecionamento, suscitando igualmente, o chamamento de seus próprios elementos para organizar sua repetição, mas também provocando, eventualmente, o apagamento, o esquecimento ou mesmo a denegação de determinados elementos" (MAINGUENEAU, 1997, p. 113).

No discurso filosófico, esse processo se diferencia na sua recursividade, pois o lugar e não lugar é uma construção paradoxal, o sentido posto no discurso filosófico e paratópico precisa se ancorar em um deslocamento de um lugar comum, onde possibilita a relação com outros lugares, ou seja, com o não lugar, o lugar não comum. Logo, o discurso filosófico por ter em si a tentativa de desfazer as noções convencionais de lugar, espaço e tempo convencionados e previstos em determinado tempo histórico, toma para si os limites da paratopia, que atua nas barreiras de validação e invalidação de discursos, enunciados e processos de enunciações. 
Nesse sentido, o discurso filosófico, apresenta formulações possíveis de um enunciado "em um dado momento, uma formação discursiva é associável a certos trajetos interdiscursivos e não a outros, e isto faz parte integrante de sua especificidade" (MAINGUENEAU, 1997, p. 118).

\section{O potencial criativo paratópico}

Como apresentado anteriormente, a partir do primado do interdiscurso, todo discurso é interdiscursivo, sendo assim o discurso filosófico é também um interdiscurso, o qual está inserido na categoria paratópica, elevando a forma de pertencimento e não pertencimento do discurso na sociedade.

Segundo Maingueneau (2010, p. 166) “os discursos "paratópicos" participam da sociedade, mas eles só os fazem porque se colocam para além dessa sociedade, porque possuem uma fronteira com o indizível e o absoluto, porque seus locutores de maior prestígio são movidos por alguma força transcendente", isto é, o discurso filosófico, assim como os precursores da filosofia, historicamente, ocupam um lugar de sobreposição aos saberes sociais, se colocando de forma similar a mitos, deuses e deusas. Sendo assim, "a paratopia pode assumir a forma de alguém que se encontra em algum lugar que não é seu, de alguém que se desloca de um lugar para o outro sem se fixar, de alguém que não encontra em um lugar" (Maingueneau, 2006; 2010 p. 166).

Maingueneau apresenta algumas categorias possíveis de pensar a paratopia, que vão ser flexibilizadas a partir da época histórica em que o sujeito está inserido, podendo ser mais marcadas ou não, mas elas que vão modalizar o discurso paratópico. 
A identidade paratópica busca criar condições de autolegitimação de um discurso. Em alguns momentos históricos, a visada paratópica dos filósofos se dava a partir de uma vida boêmia, afastada e isolada, mantendo a lógica de que nesse modo de vida se encontrava a experiência estética ou criativa. Porém, o confronto com novas realidades econômicas, institucionais e condições sociais geram novos impasses, não só de cunhos conceituais, mas de condicionamento de modo de vida. Assim, o sujeito será encapsulado e criará outros modos de afastar esse alguém de um grupo. $\mathrm{Na}$ biografia de Foucault, esse afastamento se dá pelas vias do rompimento com o convencional. Como mostra Albuquerque Junior (2010, p. 6):

"Sentindo-se um paria, Foucault busca, em sua obra e em suas reflexões, reconciliar-se consigo mesmo, reformular a imagem que tem de si. Quando em suas últimas obras começa a falar do cuidado de si, da escrita de si, a reivindicar que a vida deva ser esculpida como uma obra de arte, Foucault estará se remetendo a um outro tipo de pedagogia a um outro tipo de educação: àquela exercida por si sobre si mesmo, que chamará de subjetivação, contrapondo-a a sujeição, princípio que rege a escola em nossa sociedade. Dessa experiência dolorosa nascerá o pensador da recusa, da rebelião cotidiana contra o poder. Nascerá sua crítica profunda à instituição psiquiátrica, médica, jurídica, escolar, que chamará de intolerável. Ele então será homem feliz por ter feito trabalho de recuperação de si mesmo por meio da pesquisa, do trabalho teórico e de suas relações pessoais e políticas" (ALBUQUERQUE JUNIOR, 2010, p. 6). 
Foucault era reconhecido como um jovem incomum, que não cedia sua singularidade para as grandes convenções sociais, como a homossexualidade. Isso fez com que ele se engajasse em movimentos históricos e sociais de grande relevância, a favor dos direitos humanos e da luta racial. Mesmo politicamente, Foucault manteve-se inquieto, pois aderiu ao Partido Comunista Francês, onde também teve problemas para permanecer e travou embates históricos com os marxistas. Os impactos de se manter diferente, de se afastar de um grupo, em uma sociedade conservadora, não foi a peso de plumas, no percurso da história de Foucault, algumas vezes ele tentou o suicídio, em uma delas sendo internado no hospital Sainte-Anne.

Esse percurso mostra como Foucault faz dos seus dilemas de não pertencimento, no seu trabalho teórico e conceitual. Temáticas vistas de certa forma em seu tempo cronológico se deslocam temporalmente, pois são pensamentos à frente do tempo em que vivia. Essa existência paradoxal promove esse alguém afastado de um lugar, que permitem os conceitos de genealogia, poder, controle, biopoder, e são processos enunciativos paratópicos de tempo que afasta esse alguém de um momento, como se a teoria além de se autovalidar, também acaba tendo uma sobrevida.

Foucault faz de um não lugar da sua própria angústia, de um lugar discursivo. Essas peculiaridades do discurso filosófico que permitem situá-lo nos discursos constituintes, que têm como estatuto determinações que "podem se autorizar por si mesmo, ou seja, não pode ter outros discursos acima de si" (MAINGUENEAU, 2010, p. 158). 


\section{O lugar do discurso na autoconstituição}

Há uma relação intrínseca entre discurso paratópico e discursos constituintes, pois eles são os mesmos. Para ser constituinte, $o$ discurso tem que proporcionar uma identidade, um espaço e um lugar paratópicos e incorporar isso como estratégia do dizer para se constituir entre o lugar e o não lugar. Assim, o discurso filosófico pode ser compreendido como discurso constituinte, por ter como prisma "que seu estatuto só pode se autorizar por si mesmo" (MAINGUENEAU, 2010, p. 158). Como marca presente na soberania do discurso filosófico, são criadas ferramentas que elevam o discurso filosófico sobre os demais discursos. Assim, para se autoconstituir, há a necessidade da constituência de mundo particular que existe em paralelo ao mundo comum.

Maingueneau (2010) apresenta duas dimensões indissociáveis para a percepção do discurso constituinte:

A constituição como ação de estabelecer legalmente, como processo pelo qual o discurso instaura sua legitimidade construindo sua própria emergência no interdiscurso; os modos de organização, de coesão discursiva, a construção no sentido de um agenciamento de elementos que formam uma totalidade textual (MAINGUENEAU, 2010, p. 159).

Podemos exemplificar por meio das correntes filosóficas, que extrapolam personagens específicos, mas criam modos de organizações e construções de sentido dentro de segmentos, como o Platonísmo, Aristotelismo, Criticismo, Idealismo, entre outros. 
A partir das categorias apresentadas por Maingueneau (1997, 2010,2018) existem as dimensões indissociáveis para a compreensão do discurso constituintes: que é a retomada de discursos anteriores (o que já foi dito no próprio discurso), como ferramenta de validade da essência, pensamento e lógica de determinado discurso.

A retomada de discursos anteriores do mesmo lugar criam um processo de legitimação, por haver uma referenciação anterior dentro de um campo absoluto, que é o discurso filosófico, "esses discursos constituintes devem estar ancorados em algum absoluto: pelo fato de se autorizaram apenas por si mesmo, eles devem se apresentar como ligados a uma fonte legítima. Mas paradoxalmente, esse absoluto que se supõe como exterior ao discurso para lhe conferir sua autoridade deve, de fato, ser construídos por esse mesmo discurso para poder fundá-lo" (MAINGUENEAU, 2010, p. 159).

Pelo fato do discurso constituinte ser paradoxal, e de se criar condições de retomadas de outros pensamentos, lógicas e sentidos são permitidos a simultaneidade em ser um discurso "auto e heteroconstituinte: só um discurso que se constitui legitimando rigorosamente sua própria constituição pode exercer um papel constituinte em relação a outros discursos" (MAINGUENEAU, 2010, p. 158).

O discurso filosófico por mais que não tenha objetos próprios, constrói uma dimensão do saber, que possibilita uma identidade, que isola a dimensão figurativa, "sua enunciação se constitui mediante a própria de atribuir a si um lugar verdadeiro" (MAINGUENEAU, 2018, p. 68). 
Os filósofos sobrepõem sua identidade e sua literatura a um movimento histórico de pensamentos e saberes que atingem um alcance global, construindo comunidades discursivas que gerem e produzem instâncias de validações de uma corrente filosófica, "um discurso constituinte não mobiliza somente os autores, mas uma variedade de papéis sociodiscursivos encarregados de gerir os enunciados (...) um modo de organização social e um modo de existência dos textos" (MAINGUENEAU, 2018, p. 69).

\section{Sexualidade: a virtualidade paradoxal}

Chegamos, então, a outra etapa que incorpora a própria complexidade do objeto de estudo, a paratopia. A problemática do corpus também se apresenta, pois não está disponível para o analista de uma forma concreta. Por conta de espaço, não problematizaremos os aspectos conflitantes da noção de corpus em $\mathrm{AD}$, mas apontamos que a sua materialidade precisa se constituir como recortes que possam atender aos objetivos do analista. Relembrando, nossas perguntas norteadoras focam no que constitui o discurso filosófico como discurso paratópico e quais estratégias do dizer que o confirmam. Assim, a busca de um corpus emblemático para uma análise qualitativa se fez necessária. Encontramos essa possibilidade, a partir de recortes do capítulo 1, intitulado, como: "Nós, vitorianos" do livro a História da Sexualidade: a vontade de saber, de Michel Foucault (1988).

O livro de Foucault é resultado de um programa de pesquisa intenso que possibilitou a confecção de quatro volumes intitulados História da Sexualidade, mas que contou apenas com a publicação de três, tendo em vista que a última parte da pesquisa "Os prazeres da carne" não foi finalizado. No volume selecionado 
por nós, Foucault propõe um questionamento que possibilita um deslocamento, tanto temporal, como espacial, em relação ao sexo. Cotidianamente, até academicamente, sempre se postulou que o sexo era algo sobre o que não se falava. Sob o julgo do silêncio, a sexualidade era algo em processo de controle e deformação, tendo em vista que era negada às pessoas e às instituições a possibilidade de colocar tal questão presente em rodas de conversas cotidianas, familiares e institucionais. Esse modo de entender a presença do sexo na sociedade, motivou pesquisas e percepções históricas que construíram explicações a partir do silêncio sobre o tema. Foucault refaz o ponto de partida que dá sustentação ao modo como constrói um novo pensamento sobre sexualidade e sua história. Ele diz que, nos últimos séculos, especialmente depois da ascensão da burguesia, do capitalismo e da moralidade cristã pós Concilio de Trento, que se consolida no século XIII e XIX, nunca se falou tanto sobre sexo. Para se repensar a história a partir disso, há de se buscar na dispersão uma genealogia do pensamento que possibilita manutenção e rupturas que desembocam nas sexualidades em sua contemporaneidade. Tal ponto de partida traz o paradoxo da existência e da não existência de uma sexualidade, de um tempo que não mais pode ser usado para explicar o fenômeno, mas um entendimento da forma como a história e as interações vão reconfigurando esse lugar e não lugar do sexo e, por conseguinte, dos sujeitos e do próprio Foucault como autor que emerge desse lugar paradoxal.

No capítulo, Nós vitorianos, Foucault faz um retorno ao século XVII, para apresentar o regime vitoriano e os impasses provocados nesse período que até na contemporaneidade tem implicações nas condições de assujeitamento dos indivíduos, apresentando dessa forma a genealogia de como a "pudicícia imperial figuraria no brasão de nossa sexualidade contida, muda, hipócrita” (FOUCAULT, 1988, p. 9). 
O texto analisado tem sua representatividade por estar posicionado dentro do campo filosófico, possibilitando assim a análise dos dispositivos constitutivos do discurso filosófico e do conceito de paratopia de identidade, espacial e temporal. A análise do discurso se apropria dos marcadores históricos e ideológicos presentes na materialidade discursiva "cabe não só justificar a produção de determinados enunciados em detrimento dos outros, mas deve igualmente, explicar como eles puderam mobilizar forças e investir em organizações sociais" (MAINGUENEAU, 1997, p. 50).

Foucault organiza um modo de enunciação em que emerge como fundador de uma genealogia da sexualidade que se contrapõe à ideia de um pensar sincrônico ou contemporâneo para explicar os fenômenos tidos como mais atuais. Veja que, como filósofo, o autor não busca contar a história da sexualidade, mas por meio de sua genealogia, apreender um dispositivo de sexualidade que necessita incorporar ao modelo de pensamento filosófico, a própria história e uma forma de historicidade ao fenômeno do sexo e suas consequências na constituição dos sujeitos e controles políticos. Assim, o autor constrói uma lógica histórico-teórica, histórico-política utilizando de acontecimentos da época clássica e da Idade Moderna, possibilitando uma paratopia temporal que dão efeito de garantia para seu pensamento. $\mathrm{O}$ que é colocado em jogo no discurso são marcas no texto que apresentam percursos históricos, com datas, séculos, especificidades de um tempo social em comparação aos outros, sendo uma "constituição como ação de estabelecer legalmente, como processo pelo qual o discurso instaura sua legitimidade construindo sua própria emergência no interdiscurso" (MAINGUENEAU, 2010, p. 159).

Segundo Maingueneau (2010), uma obra constituinte representa seu papel não somente pelo conteúdo que ela veicula, mas também pelos modos de enunciação que ela autoriza. No texto de 
Foucault, é perceptível a habilidade verbal para apresentar o percurso histórico e acuidade do raciocínio filosófico que se apresenta para além de uma construção de um saber verdadeiro ou falso, criando assim uma maior legitimidade para o texto com um status de saber para além das crenças ou de opiniões empíricas.

No Recorte 1, é possível analisar como dispositivo dialogal, a organização enunciativa em que Foucault fundamenta sua crítica. $\mathrm{O}$ autor realiza recortes históricos enxertando uma construção teórica atravessada por eventos sociais de determinadas épocas, onde a relação do autor e leitor extrapola a teoria, mas vai de encontro a uma teoria embasada historicamente:

\section{Recorte 1}

Diz-se que no início do século XVII ainda vigorava uma certa franqueza. As práticas não procuravam o segredo; as palavras eram ditas sem reticência excessiva e, as coisas, sem demasiado disfarce; tinha-se com o ilícito uma tolerante familiaridade. Eram frouxos os códigos da grosseria, da obscenidade, da decência, se comparados com os do século XIX (FOUCAULT, 1988, p. 9).

A retomada do século XVIII rompe com a possibilidade de pertencimento a um mundo ético e moral que conhecemos. $\mathrm{O}$ autor, ao trazer uma outra dimensão de realidade, embora histórica, elucida um lugar que nega o lugar cotidiano reservado às práticas sexuais. A franqueza ao ato sexual, a falta de mistério, a tolerância que possibilita a grosseria, a obscenidade revela um mundo quase virtual que nos constitui. O lugar é problemático na medida em 
que o discurso filosófico o permite existir enquanto uma explicação paratópica, mas negada como possibilidade de nos constituir de forma mais concreta. É um lugar virtual, fictício que se legitima, pelas condições de produção do discurso filosófico, por uma instância de autor que se coloca acima no cotidiano moralista que regra as práticas sexuais.

Está implicada aqui, uma paratopia criativa marcada pela existência do escritor e a não existência do autor. O conflito motivador dos questionamentos do sujeito no mundo, faz refletir e chegar à categoria de autor que busca a existência de personagens quase fictícios para incorporá-los no eixo de uma lógica de explicação da emergência da sexualidade que são negados pela sociedade. Dizer que "Eram frouxos os códigos da grosseria, da obscenidade, da decência, se comparados com os do século XIX" implica em trazer para a nossa existência contemporânea o sujeito grosso, obsceno e indecentes que nos constituem. Ora, se nos constituímos desses sujeitos, em que medida posso concordar, uma vez que o sujeito está encapsulado pelas regras de uma dada moralidade que determina os jogos da sexualidade e suas determinações. Apenas o autor e o discurso filosófico podem legitimar a emergência dessa lógica. Os códigos de controle se opõem aos códigos frouxos, por isso, nas palavras do autor, evidenciam uma sexualidade "polimorfa", "perversa". Aquela sexualidade, portanto, latente, existencialmente problemática, objeto de uma "scienta sexualis", ou seja, de um olhar que a distância da sua essência e da essência do ser. O que se opõe ao que chama "ars erótica", vista na cultura oriental, por exemplo.

Aqui, cabe um esclarecimento, não estamos falando do escritor ou do sujeito no mundo, caso o efeito de sentido depreendido crie a resistência aos leitores que concluiriam ser prematuro dizer que a própria condição do escritor determinaria sua obra. Por isso mesmo, estamos na dimensão dos efeitos de sentido, mas não das intenções da existência real. 
Da mesma forma que justificamos, Foucault apresenta as condições de produção discursiva que geram e produzem os efeitos de sentido e discursos sobre a história da sexualidade:

\section{Recorte 2}

Em suma, gostaria de desvincular a análise dos privilégios que se atribuem normalmente à economia de escassez e aos princípios de rarefação, para, ao contrário, buscar as instâncias de produção discursiva (que, evidentemente, também organizam silêncios), de produção de poder (que, algumas vezes têm a função de interditar), das produções de saber (as quais, frequentemente, fazem circular erros ou desconhecimentos sistemáticos); gostaria de fazer a história dessas instâncias e de suas transformações (FOUCAULT, 1988, p.14).

Os paradoxos conflitivos apontados nesse recorte por Foucault "não mobiliza somente autores, mas uma variedade de papéis sociodiscursivos encarregados de gerir os enunciados", as fronteiras entre um lugar e um não lugar é o que alça o discurso para um “além”, em que se dá um efeito que esse alguém está afastado de um momento. Mas, se retomarmos alguns elementos do texto e da história de Foucault, veremos que o lugar é ambivalente ou até mesmo ambíguo.

"Gostaria de desvincular a análise dos privilégios", "produção discursiva que, evidentemente, também organizam silêncios", 
"função de interditar", faremos alguns comparativos com o momento histórico de Foucault, mas não de forma ingênua, ou seja, dizendo que todo ponto A leva necessariamente ao ponto $\mathrm{B}$, mas que os lugares paradoxos.

Vejamos: "Em 1948 Foucault é internado pelo pai no hospital Sainte-Anne após tentativa de suicídio", "Foucault vivencia com muita culpa e vergonha sua condição de homossexual", "filia-se ao Partido Comunista Francês, o PCF”. A rede de enunciados como interdição, silêncios, movimentos políticos, lutas de poderes, perpassa ao paradoxo entre a historicização da subjetividade do Foucault, ou seja, o real da história marca uma posição subjetiva, como dito anteriormente não podemos dizer que necessariamente um fator levou linearmente ao outro, mas existem implicações nas formações enunciativas da teoria foucaultiana como um "sistema de relações que permite que cada discurso se instaure e se mantenha" (MAINGUENEAU, 2018, p. 68).

O regime de "constituência" no discurso filosófico gera um caráter de irredutibilidade, um lugar que excede todos os outros lugares, que segundo Maingueneau representa, um:

Dispositivo enunciativo que deixa perceber de sua própria instauração e a validação retrospectiva que se realiza de suas modalidades sociais de existência: um modo de difusão dos textos, uma distribuição da autoridade enunciativa, um tipo de exercício de poder reivindicado ou denunciado pelo gesto que instaura a obra (MAINGUENEAU, 2018, p. 70).

O desejo expressado por Foucault de transformação e reconstituição da percepção histórica também implica em uma autorida- 
de enunciativa, a um poder que é reivindicado pela instância do filósofo. "Em suma, gostaria de desvincular... Gostaria de fazer a história dessas instâncias...", a polidez marcada pelo uso do futuro do pretérito não permite a destituição da autoridade de quem de fato fará o que diz que gostaria de fazer. A estratégia do dizer paratópico, a paratopia criativa e o status conferido ao filósofo, papel central no discurso constituinte, fecham a rede que o colocam no patamar de enunciador que ocupa o lugar do absoluto.

Assim, o discurso filosófico vai se retroalimentar a partir das retomadas enunciativas que criam um processo de legitimação dada por essa autoridade, para as quais serão criados encapsulamentos interdiscursivos, se formula a partir de um constructo de autoridade, a partir de enunciados particulares. É para sustentar esses desejos que Foucault vai retomar outros saberes, outras histórias e historiadores, outras correntes filosóficas, incorporando-as em sua própria enunciação como fonte irradiadora de sentido.

Por isso, o discurso paratópico se sobrepõe aos saberes sociais, se colocando de forma similar a mitos, deuses e deusas. Sendo assim, "a paratopia pode assumir a forma de alguém que se encontra em algum lugar que não é seu, de alguém que se desloca de um lugar para o outro sem se fixar, de alguém que não encontra em um lugar” (MAINGUENEAU, 2006; 2010, p. 161). Quando Foucault apresenta saberes sobre a história da sexualidade são realizados deslocamentos para discutir a temática proposta.

Sendo assim, na obra analisada é possível identificar a paratopia de identidade que afasta esse alguém de um grupo, onde, por meio do movimento enunciativo Foucault se distancia de um aspecto valorativo, utilizando do movimento histórico para realizar críticas e ponderações sobre a história da sexualidade; a paratopia espacial que afasta esse alguém de um lugar, o modo de enunciação 
posto por Foucault adquiriu uma universalidade e/ou uma genealogia sobre a história da sexualidade, fazendo com que sua obra adquira um valor para além de um grupo; paratopia temporal que afasta esse alguém de um momento, as ideias propostas pela obra de Foucault, ainda tem efeito na contemporaneidade.

\section{Conclusão}

Nosso estudo buscou uma reflexão que pudesse sustentar a aplicação da noção de paratopia no discurso filosófico a partir das categorias de lugar, espaço e tempo, como tratou essencialmente, Maingueneau (2018). Por se tratarem de categorias complexas, as paratopias, como estratégias do dizer, precisam ser aprofundadas e testadas em outros discursos que foram apenas apontados no discurso literário, mas não analisados de uma maneira mais produtiva. Assim, buscamos evidenciar, a partir da obra "História da Sexualidade: a vontade de saber", de Michel Foucault, como a paratopia criativa e a instância de enunciador paratópico podem se concretizar. A reciprocidade entre as condições de produção do escritor e a emergência do autor mostram que a paratopia criativa é o motor da criação da obra e da existência paradoxal do filósofo, dado que é na posição insustentável consigo e com o mundo que o sujeito irá construir outros sentidos de lugar, espaço e tempo, deslocando-se do convencional.

As categorias de paratopia de identidade, lugar e tempo são as articulações que fornecem e consolidam a legitimidade do modo de dizer que estabelece modos de organização específicos de acesso ao interdiscurso, ligando as condições de produção à obra, ou seja, por não estar satisfeito com as narrativas já ditas sobre a sexualidade, é o que Foucault teve como movimento criador e de rompimento com o já dito sobre a temática. 
As três categorias tecem e viabilizam a emersão da paratopia no discurso filosófico de Foucault, uma vez que no indizível e absoluto, nas retomadas históricas, nos incômodos da existência de Foucault, que é gerida a inscrição enunciativa como discurso paratópico.

Não poderíamos chegar a essas conclusões sem, no entanto, atrelar à paratopia outros conceitos necessários e constitutivos desse não lugar, como o próprio conceito trazido de filosofia. Para além disso, foi preciso entender que o modo de dizer paratópico só faz sentido dentro de um discurso constituinte que, reciprocamente, legitima sua paratopia que, ao mesmo tempo, a constitui.

\section{Referências}

ABBAGNANO, Nicola. Dicionário de filosofia. Tradução da $1^{\text {a }}$ edição brasileira coordenada e revisada por Alfredo Bossi$5^{\mathrm{a}}$ ed.- São Paulo: Martins Fontes, 2007.

ALBUQUERQUE JÚNIOR, Durval Muniz de. O pensador de todas as solidões. Revista Educação - Especial Foucault pensa a educação, São Paulo, 2010, v. 3.

CANO, Rogério de Oliveira. A manifestação dos estados de violência no discurso jornalístico. Tese (Doutorado em Língua Portuguesa) - Pontifícia Universidade Católica de São Paulo, São Paulo.

CHARAUDEAU, Patrick. "Dize-me qual é teu corpus, eu te direi qual é a tua problemática”. Revista Diadorim / Revista de Estudos Linguísticos e Literários do Programa de Pós-Graduação em Letras Vernáculas da Universidade Federal do Rio de Janeiro. Volume 10, Dezembro 2011. 
FOUCAULT, Michel. História da sexualidade. Tradução de Maria Thereza da Costa Albuquerque e J. A. Guilhon Albuquerque. Rio de Janeiro, Edições Graal, 1988.

MAINGUENEAU, Dominique. Discurso literário. Tradutor Adail Sobral. - 2. Ed., São Paulo: Contexto, 2018.

MAINGUENEAU, Dominique. Doze conceitos em análise do discurso. Organização Sírio Possenti e Maria Cecília Perez de Souza-e-Silva; tradução Adail Sobral- São Paulo- Parábola Editora, 2010.

MAINGUENEAU, Dominique. Gênese dos discursos. Trad. Sírio Possenti. Curitiba: Criar Edições, 2007.

MAINGUENEAU, Dominique. Novas tendências em análise do discurso. $3^{\mathrm{a}}$. ed. Trad. Freda Indursky. Campinas: Pontes, 1997. 